\title{
Life on Mars: time to start
}

\section{Bianciardi G}

Department of Medical Biotechnologies, University of Siena, Siena, Italy

*Corresponding author: Bianciardi G, Department of Medical Biotechnologies, University of Siena, Siena, Italy, Tel: +39 348 2650891; E-mail: giorgio.bianciardi@unisi.it

\section{Rec date: November 03, 2015; Acc date: November 05, 2015; Pub date: November 09, 2015}

Copyright: $(2015$ Bianciardi G. This is an open-access article distributed under the terms of the Creative Commons Attribution License, which permits unrestricted use, distribution, and reproduction in any medium, provided the original author and source are credited.

\section{Editorial}

All the data we have gathered after a lot of NASA missions are consistent with life.

The reader remembers the Labeled Release (LR) experiment on NASA's Viking missions, 1976: it satisfied the pre-mission criteria for the detection of microbial life on Mars [1]. Soon after, the claim that extant life was found was disputed by several alternative hypotheses. This resistance focused primarily on the (supposed) absence of liquid water on the surface of Mars (being the Martian atmospheric below the triple point pressure of water, $610 \mathrm{~Pa}$, water can exists there only as a solid or vapor), and on the failure of the Viking chromatograph-mass spectrometer (GC-MS) to find any organic matter.

To this day, the picture has been changed.

Liquid water on Mars, The Rover Environmental Monitory Station instrument aboard on Curiosity rover was clearly able to show that the Martian atmospheric pressure DID NOT FALL (at Gale Crater) below $610 \mathrm{~Pa}$. Moreover, atmospheric and ground temperatures frequently peaked above $0 \mathrm{C}$. Liquid water can exist on Mars. The large amount of water vapor that was released when Martian samples have been heated may prove directly the presence of liquid water [2].

Organic compounds. Sample analysis at Mars (SAM) aboard on Curiosity rover confirmed the detection of chloromethane, dichloromethane, and trichloromethane, yet detected by the GC-MS aboard on Vikings. It is very difficult, to-day, to invoke "terrestrial contamination". 1) "Blanks" analyzed prior to the Martian sample contains a lower amount of these organic compounds 2) The paper by Navarro-Gonzalez et al [3] clearly showed that, in the oxidant environment present on Mars, instruments like GC-MS and SAM causes the destruction of complex organic compounds, producing chloromethane, dichloromethane, and trichloromethane 3) At the Lunar and Planetary Science Conference, March 2015, Danny Glavin, a SAM scientist at Goddard, reported the presence on Martian samples of compounds consistent with: an eight-carbon molecule akin to a benzoic acid, an 11-carbon alcohol-like molecule, and a 10-carbon molecule, attributable to a fatty acid-like carboxylic acid [4]. The last one being the type that cell walls are made of. Interestingly, Curiosity rover was also able to detect methane, confirming previous data. A curiosity methane observation was reported in the Jan 23 issue of Science [5]. Methane release was variable but, however, quite similar to Earth-based and Mars Express/Mars Global Surveyor observations [6-8]. Whether this is evidence of geochemistry or biology is of course controversial. There is the possibility that methane release on Mars be produced by a geochemical process such as serpentinization, but, methane on Earth is often associated with biological activity.

We have enough data to affirm, now, that on Mars the presence of life is plausible. NASA and ESA have not yet sent probes capable of doing biological analysis (after the Vikings), and we need to wait years before the Agencies are sending probes dedicated to the purpose. Certainly, we can ask to NASA to redirect the rover Curiosity to experiments able to support the presence of life on Mars, as we are attempting to do (UK Space Agency, Barry DiGregorio Principal Investigator, Levin, Ron Dorn, Robert Lodder and myself, Co-I: "A Search for Extant Endolithic and Hypolithic Microbial Communities in Broken and Overturned Rocks by the MSL Rover Wheels using MAHLI"). The proposal seeks to use the spectroscopic filters on the Mast Camera and MAHLI microscopic imager camera on the Curiosity to look for evidence of methane and microorganisms in broken rocks (the Review Process will be ended on November 2015. good luck!).

But we have a huge amount of data, chemical and morphological, that we have received from a large number of probes sent to the Red Planet in the past 20 years. In that way, the writer was able to reanalyze the signals from the Viking Labeled Release Experiments in order to search for chaotic bio-indexes [9], or to search for morphological-morfometric biosignatures in the Athena images obtained by Opportunity rover [10] or Spirit rover (this issue). I'm sure a lot of information is still hidden within pictures or chemical analysis provided by the probes. Hidden information able to support the presence of life on Mars is just waiting skilled investigators who are able to come up with the right approaches to reveal it.

\section{References}

1. Levin GV, Straat PA (1977) Life on Mars? The Viking labeled release experiment. Biosystems 9: 165-174.

2. Levin GV (2013) Evidence for microbial life on Mars? SPIE.

3. Navarro-Gonzalez R, Vargas E, Jose de la Rosa, Raga AC, Mckay CP (2010) Reanalysis of the Viking results suggests perchlorate and organics at midlatitudes on Mars. JGR 115: E12.

4. Hand E (2015) Mars rover finds long-chain organic compounds. Science 347: 1402-1403.

5. Webster CR, Mahaffy PR, Atreya SK, Flesch GJ, Mischna MA, et al. (2015) Mars methane detection and variability at Gale crater. Science 347: 415-417.

6. Krasnopolsky VA, Maillard JP, Owen TC (2004) Detection of methane in the martian atmosphere: evidence for life? ICARUS 172: 537-547.

7. Mumma MJ, Villanueva GL, Novak RE, Hewagama T, Bonev BP, et al. (2009) Strong Release of Methane on Mars in Northern Summer 2003. Science 323: 1041-1045.

8. Formisano V, Atreya S, Encrenaz T, Ignatiev N, Giuranna M (2004) Detection of Methane in the Atmosphere of Mars. Science 306: 1758-1761.

9. Bianciardi G, Miller JD, Straat PA, Levin GV (2012) Complexity Analysis of the Viking Labeled Release Experiments. IJASS 13: 14-26.

10. Bianciardi G, Rizzo V, Cantasano N (2014) Opportunity Rover's image analysis: Microbialites on Mars? IJASS 15: 419-433. 